\title{
Acidentes químicos ampliados: um desafio para a saúde pública
}

\author{
The increase in chemical accidents: a challenge for public health \\ Carlos M. de Freitas, Marcelo F. de S. Porte e Carlos M. Gomez \\ Centro de Estudo da Saúde do Trabalhador e Ecologia Humana. Escola Nacional de Saúde \\ Pública (FIOCRUZ) - Rio de Janeiro, RJ - Brasil
}

\begin{abstract}
Os acidentes envolvendo subståncias perigosas nas atividades de transporte, armazenamento e produçāo industrial de produtos químicos constituem um sério risco à saúde e ao meio ambiente. Objetiva-se discutir, no âmbito da saúde pública, alguns dos desafios que esses tipos de acidentes colocam, principalmente para os palses de economia perlférica. Através da combinaçăo de informaçðes quantitativas e qualitativas, foram definidos e caracterizados esses tipos de acidentes e seus diversos riscos. Esses acidentes tém se apresentado com a maior gravidade nos países de economia periférica, embora a maioria deles venha ocorrendo sem o adequado registro de informações básicas para a avaliação e vigilância, como é demonstrado no caso do Rio de Janeiro (Brasil). Além da tarefa de se avaliar as conseqúéncias de eventos, por vezes extremamente complexos, coloca-se também, a de formular estratégias de controle e prevenção em realidades sociais que configuram um terreno fértil para a ocorrência e agravamento dos mesmos.
\end{abstract}

Acidentes químicos. Acidentes industriais. Saúde do trabalhador. Saude ambiental.

\section{Introdução}

No ano de 1994 foram realizados no Brasil alguns eventos que trouxeram para a saúde pública mais um desafio a ser enfrentado, entre tantos outros. A Organização Internacional do Trabalho e o Ministério do Trabalho organizaram o Seminário Nacional de Prevenção de Acidentes Maiores, no mês de maio na Bahia, e o Seminário Latino-Americano Tripartite Sobre Acidentes Industriais Maiores, no mês de agosto em São Paulo. O Programa Internacional de Segurança Química da Organização Mundial de Saúde realizou em São Paulo, no mès de junho, o Simpósio IPCS Sobre o Gerenciamento dos Aspectos Ambientais $e$ de Saúde de Acidentes com
Substâncias Químicas. O Centro de Estudos da Saúde do Trabalhador e Ecologia Humana da Escola Nacional de Saúde Pública da Fundação Oswaldo Cruz promoveu em dezembro o seminário 10 Anos de Bophal - O Acidente Químico Maior em Questão.

Essas programações colocam a problemática dos acidentes químicos ampliados, capazes de produzirem múltiplos danos num único evento, possuindo também o potencial de provocarem efeitos que se estendem para além dos locais e momentos de sua ocorrência. Por um lado, está a dificuldade de se avaliar as consequiências de acidentes, por vezes extremamente complexos. Por outro lado, encontra-se o desafio de formular estratégias de controle e prevenção de acidentes com caracterís- 
ticas bastante diversifjcadas. A discussão desse tipo de acidente no âmbito da saúde pública - objetivo central do presente artigo - é, uma exigência da qual não cabem omisșōes.

\section{Breve Histórico}

A importância dos acidentes químicos está diretamente relacionada em evolução histórica da produção e consumo de substâncias químicas em nível internacional e nacional. A partir da II Guena Mundial, o aumento da demanda por novos materiais e produtos químicos, acompanhado pela mudança da base de carvão para o petróleo, conduzí ao desenvolvimento e expansão do complexo químico indústrial ${ }^{33}$. A natureza altamente competitiva desse setor industrial, aliada ao crescimento da economia em escala mundial e ao rápido avanço da tecnologia, possibilitaram o aumento das dimensōes das plantas industriais e da complexidade dos processos produtivos ${ }^{64.66}$.

Nos anos 60, uma planta industrial para craquear nafta e produzir 50.000 toneladas/ano de etileno era considerada de grande porte. A partir dos anos 80, plantas para a produção de etileno e propileno ultrapassaram a escala de 1 milhão de toneladas $s^{6.7 \%}$. O transporte e o armazenamento seguiram o mesmo ritmo. A capacidade dos petroleiros no pós-guerra cresceu de 40.000 toneladas para 500.000 toneladas e a de armazenamento de gás de $10.000 \mathrm{~m}^{3}$ para $120.000 / 150.000$ $\mathrm{m}^{30 t}$. Nesse período verifica-se que a comercialização mundial de químicos orgânicos passou de 7 milhões de toneladas em 1950 para 63 milhöes, em 1970, 250 milhöes, em 1985, e 300 milhöes, em $1990^{43}$.

$\mathrm{O}$ crescimento das atividades de produção, armazenamento e transporte de substâncias químicas em nível global provocou um aumento no número de seres humanos expostos aos seus riscos - trabalhadores e comunidades ${ }^{\star x}$. Paralelamente, observa-se aumento na freqüência e gravidade dos

*De acordo com Drogaris":, sâo atualmente propostos seis indices de gravidade (negligenciâvel, digno de nota, importante, severo, muito severo e catastrófico, em basicantente três grupos de parâmetros (potencial de perigo em função do tipo e quantidade da substância envolvida, consequências - saúde, meio ambiente e materiais - e extensäo das medidas externas de intemençâo e segurançal para os acidentes quimicos ampli. ados ocorridos nas Comunidades Européias. Um dos índices empregados no grupo de parâmetros das consequiencias é o mimero de óbitos, sendo classificados como "importante". (entre 1e 4), "severos" (entre 5 e 19). "muito severos" (entre 20 e 49) e "catastroficos" (mais de $50 \%$. acidentes químicos nessas atividades. Os acidentes com 5 óbitos ou mais, os quais são considerados muito severos*, passaram de 20 (média de 70 óbitos por acidente) entre 1945 e 1951, para 66 (média de 142 óbitos por acidente) entre $1980 \mathrm{e}$ $1986^{29}$.

\section{Os Acidentes Químicos Ampliados}

A própria nomenclatura desses tipos de acidentes ainda não se encontra consolidada e varia de país para país. São freqüentemente denominados de acidentes maiores, uma tradução literal da expressão major accidents em inglês ou accidents majeurs em francês. Em Portugal, no entanto, são definidos como acidentes industriais graves e na Alemanha como Störfall, cuja tradução literal seria algo como acidente de perturbação. Em nossa concepção, o termo maior induz a pressupor, de forma técnica e eticamente equivocada, como de menor importância os outros tipos de acidentes. No presente artigo propõe-se denominar esses acidentes como acidentes ampliados, ou. mais especificamente, acidentes químicos ampliados, uma vez que se restringirá somente aos envolvendo substâncias e produtos químicos. Esta terminologia parece ser mais apropriada ao sentido dado no presente artigo, expressando a possibilidade de ampliação no espaço e no tempo das consequièncias dos mesmos sobre as populaçōes e o meio ambiente expostos.

Segundo a Diretiva de Seveso, de 1982. do Conselho das Comunidades Européias ${ }^{23}$, esses tipos de acidentes provêm de "uma ocorrência, tal como uma emissão, incêndio ou explosão envolvendo uma ou mais substâncias químicas perigosas, resultando de um desenvolvimento incontrolável no curso da atividade industrial, conduzindo a sérios perigos para o homem e o meio ambiente, imediatos ou a longo prazo, internamente e externamente ao estabelecimento".

$\mathrm{Na}$ base de dados internacional "Major Hazard Incident Data Service (MHIDAS)", são considerados incidentes/acidentes** ampliados não só os situados no processo de produção industrial, mas também os de transporte e armazenagem de químicos que resultem em potencial de perigo para a comunidade ${ }^{14}$. No campo da saúde, esses acidentes têm sido definidos de forma similar. com ênfase na

\footnotetext{
** Incidentes säo compreendidos neste artigo como eventos inesperados sem sérias consequiências, embora possam ocasioná-las. Já os acidentes corresponden a eventos também inesperados. porém que causam danos materiais, lesóes e óbitos.
} 
gravidade e extensāo dos agravos à saúde que podem provocar, freqüentemente, em um grande número de seres humanos ${ }^{34,57}$.

Considera-se, portanto, acidentes químicos ampliados os eventos agudos, tais como explosões, incêndios e emissões, individualmente ou combinados, envolvendo uma ou mais substâncias perigosas com potencial de causar simultaneamente múltiplos danos ao meio ambiente e à saúde dos seres humanos expostos. O que caracteriza os acidentes químicos ampliados não é somente sua capacidade de causar grande número de óbitos, embora sejam freqüentemente conhecidos exatamente por isto. É também o potencial da gravidade e extensāo dos seus efeitos ultrapassarem os seus limites espaciais - de bairros, cidades e países - e temporais - como a teratogênese, carcinogênese, mutagênese e danos a órgãos alvos específicos ${ }^{6.8,29,34,53,57}$.

\section{Características dos Acidentes Químicos Ampllados}

Em termos quantitativos, os acidentes químicos ampliados nas atividades de produção situam-se entre $40 \%$ e $50 \%$ \$.4.29,64. Para o transporte, os percentuais variam entre $46 \% \%^{29}$ e $15 \% \%^{8.64}$ e no armazenamento estão situados entre $33 \%^{8}$ e $16 \%^{29,64}$.

Em relação às vítimas fatais em acidentes ampliados ocorridos no mundo, entre 1945 e 1986 , com mais de 5 óbitos, os situados no transporte ( $46 \%$ do total de acidentes) foram responsáveis por $45 \%$ das mortes, enquanto as instalações fixas ( $40 \%$ do total de acidentes) por cerca de $47 \%{ }^{29}$. Um estudo realizado em 1990 pela "Agency for Toxic Substances and Disease Registry (ATSDR)", em cinco estados dos EUA., mostrou que $91 \%$ das vítimas em indústrias onde ocorreram esses acidentes eram os próprios trabalhadores*. No "Major Accidents Report System (MARS)", sistema de informação para as Comunidades Européias sobre esses tipos de eventos, dos 121 acidentes registrados entre 1980 e 1991, 49,6\% tiveram vítimas ${ }^{22}$. Do total de 878 vítimas, $44,3 \%$ foram trabalhadores das próprias indústrias $\mathrm{e}$ $52,8 \%$ pessoas externas, sendo $2,8 \%$ não identificados. Embora os acidentes químicos ampliados sejam conhecidos principalmente pelos seus impactos nas populações circunvizinhas, a análise dos dados do MARS revela serem os trabalhadores

\footnotetext{
* Comunicação pessoal de G. Jones durante "Simpbsio IPCS" sobre Gerenciamento dos Aspectos Ambientais e de Saúde, de Acidentes com Substâncias Quimicas, CETESB, 1994.
}

as principais vítimas fatais, destes acidentes (94\%), enquanto que, para as vítimas nāo-fatais predominou a população externa, com $56,2 \%$.

As explosões são os eventos com maior frequiência de grande número de óbitos imediatos (Tabela.1), porém as emissões acidentais e os incêndios, estes últimos envolvendo a combustão de substâncias químicas e formação de nuvens tóxicas, não são menos perigosos. Estes dois últimos tipos, os quais segundo os dados do MARS estiveram presentes em $98,4 \%$ dos 121 acidentes químicos ampliados registrados, ao contrário das explosōes, nāo têm os seus riscos circunscritos ao espaço e tempo dos acidentes. Podem se ampliar tanto em termos espaciais, atingindo outras cidades ou países, como em termos temporais, atingindo as gerações futuras.

A súbita liberação de energia provocada pelas explosôes pode tomar diversas formas. Os efeitos das explosöes físicas tendem a ser locais, porém as explosōes químicas podem ter amplas repercussões, uma vez que podem resultar em incêndios e emissões de substâncias tóxicas perigosas. Em ambas as formas, há ainda a possibilidade de lançamento de fragmentos ${ }^{12}$. Além dos danos patrimoniais que ocorrem na maioria desses eventos, alguns têm resultado na morte imediata de grande número de pessoas (trabalhadores e comunidades próximas), provocada por queimaduras, traumatismos e sufocaçāo pelos gases liberados após as explosôes, bem como lesōes para um número ainda maior ${ }^{37.59 .74}$.

No caso dos incêndios, além da radiação de calor e dos possíveis incêndios e explosões adicionais, existem ainda os riscos associados à própria combustão das substâncias químicas envolvidas, resultando na emissão de múltiplos gases e fumaças tóxicas e atingindo áreas distantes. A combustão de PVC, por exemplo, pode gerar 75 produtos diferentes $^{47}$ e no incêndio do depósito de produtos químicos da Sandoz em 1986, localizado em Schweizerhalle/Suiça, estimou-se que no mínimo 15.000 produtos podem ter sido gerados pela combustāo basicamente de agrotóxicos organofosforados e compostos de mercúrio orgânico'.

Esta característica dos incêndios químicos tem tornado difícil estabelecer inferências causais entre a possível exposição e os sintomas específicos registrados, tal como evidenciam os estudos sobre bombeiros ${ }^{531.47}$ e populações expostas a estes tipos de eventos'.

As águas residuais contaminadas dos combates aos incêndios químicos são outra fonte de riscos, tanto para as equipes de emergências que entram 
Tabela 1 - Acidentes químicos ampliados em nivel global com mais de 20 óbitos do inicio do século até 1984.

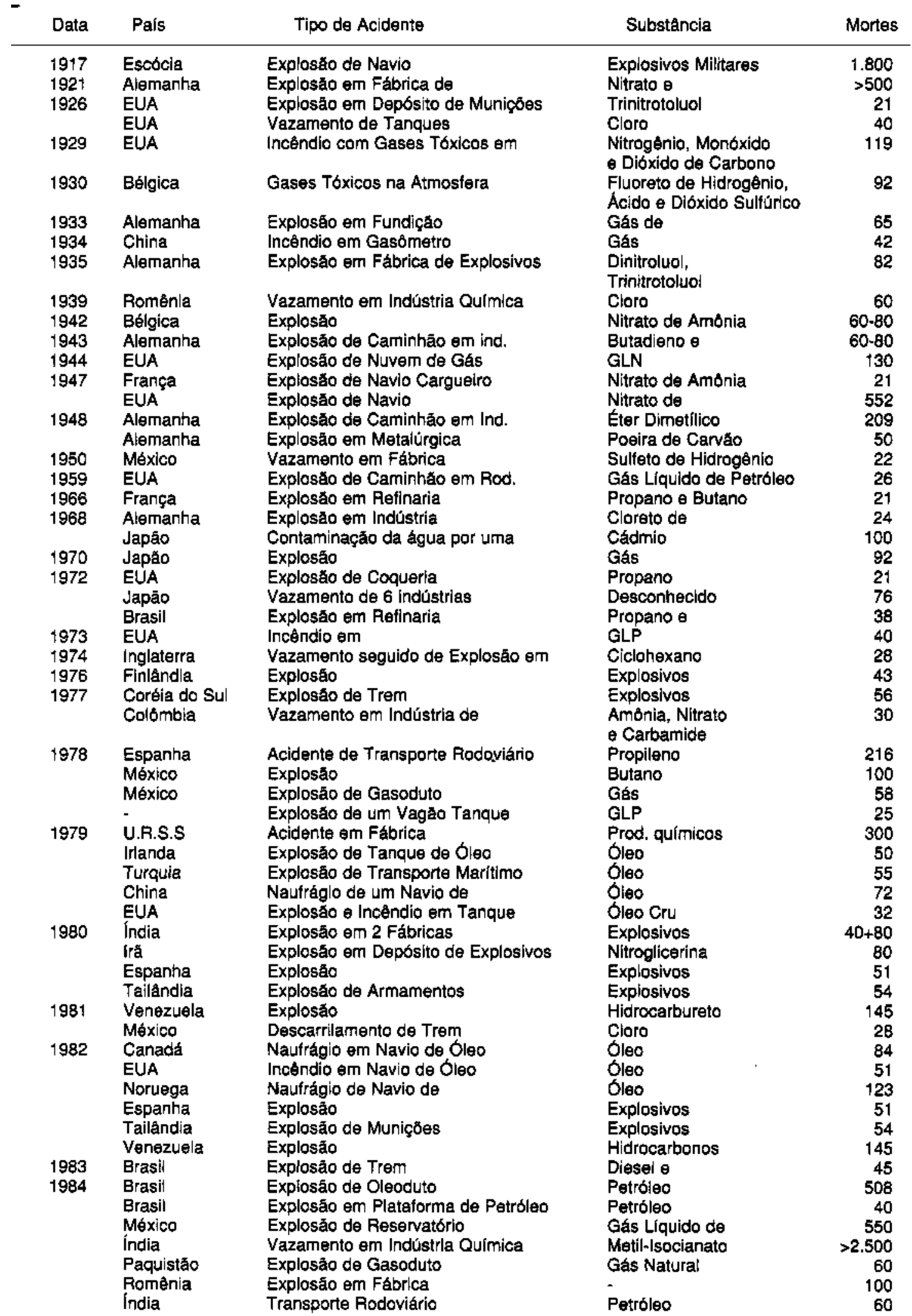

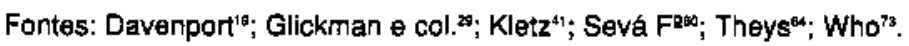


em contato com estas durante o combate ${ }^{63}$, como para as populaçð̄es que obtêm sua água para consumo dos rios atingidos ${ }^{1}$. No combate ao incêndio da Sandoz, estimou-se que entre 10 e 30 toneladas de contaminantes foram lançadas no rio Reno através das águas residuais, resultando na morte de grande número de peixes numa extensão de $250 \mathrm{~km}^{32}$ e colocando sob risco uma populaçāo estimada em 12 milhōes de habitantes distribuídos por cidades e vilas ao longo desse rio na França, Alemanha e Holanda'.

Esses eventos, apesar de não serem responsáveis por grande número de óbitos imediatos (Tabela. 1), podem causar muitos danos à saúde dos seres vivos expostos e ao meio ambiente, a curto e longo prazos. As incertezas quanto aos próprios efeitos sobre a saúde e o meio ambiente também podem provocar sentimentos de medo, insegurança e mesmo pânico e instabilidade social nas regióes afetadas ${ }^{43}$, conduzindo em alguns casos ao estresse nas populaçzes expostas ${ }^{3}$. As características fisico-químicas das emissōes acidentais são determinantes de sua toxicidade, vias de exposição e extensão das áreas atingidas. A forma sólida tem menor capacidade de se estender além dos limites da zona afetada, sendo mais freqüente em casos de armazenamento ou disposição inadequada de resíduos.

As emissōes líquidas acidentais, que freqüentemente ocorrem diretamente por vazamento ou derramamento, têm sua extensão determinada, entre outros fatores, pela existência de cursos d'água e barreiras naturais ou artificiais ${ }^{\text {s4 }}$. Na contaminação de corpos d'água para consumo, tal como incêndio da Sandoz, milhares de pessoas podem ser colocadas sob risco ${ }^{1,20,39,71}$.

As emissões de gases $e$ vapores tóxicos na atmosfera apresentam maiores possibilidades de dispersăo, podendo atingir grandes extensões e um número maior de pessoas, constituindo a forma predominante de exposições ambientais e ocupacionais ${ }^{46}$. A gravidade e extensão dessas emissరెes dependem das propriedades físico-químicas, toxicologicas e ecotoxicológicas das substâncias envolvidas, bem como das condições atmosféricas, geológicas e geográficas.

Essas emissōes, assim como os incêndios, podem provocar efeitos tanto agudos quanto crônicos, como carcinogenicidade, teratogenicidade, mutagenicidade e danos a órgãos-alvos específicos ${ }^{6.57}$. Um único evento deste tipo pode se constituir em verdadeira catástrofe, tal como ocorrido no maior acidente químico da história em Bophal, na Índia, em 1984 (Tabela 1).

\section{Seveso: O Protótipo do Acidente Químico Ampliado}

Conforme observam Bertazzi e col. ${ }^{30}$, embora o acidente de Seveso possua características que lhe são específicas, pode representar um protótipo exemplar dos perigos à saúde e ao meio ambiente associados à produçăo industrial de substâncias químicas. $O$ acidente ocorreu no dia 10 de julho de 1976 na indústria química Icmesa. Uma reação inesperada em um reator provocou o rompimento do disco de segurança, resultando na emissão atmosférica de una nuvem tóxica contendo triclorofenol, triclorofenato de sódio, etileno glicol, hidróxido de sódio e substanciais quantidades de dioxina.

A nuvem contendo dioxina liberada no acidente se estendeu por uma grande área ( 1.786 hectares), atingindo 37.234 seres humanos, não tendo sido detectada imediatamente a gravidade do mesmo. Poucos dias após a emissăo, foram observados sinais de uma séria contaminaçāo ambiental, incluindo danos à vegetação, aos pássaros e aos animais domésticos. Especialmente entre as crianças ocasionou queimaduras, lesões caústicas e inflamaçōes nas partes não cobertas do corpo, surgindo logo após a cloracne em 193 pessoas, sendo 170 em menores de 15 anos $^{9.10}$. A demora no fornecimento de informaçōes, por parte da indústria, contribuiu para que as açōes de emergência fossem iniciadas somente quando se evidenciaram os danos ao meio ambiente e à saúde.

Alguns dos ingredientes que compuseram esse acidente se encontram presentes em grande parte dos acidentes químicos ampliados. $\mathrm{O}$ primeiro é a localização muito próxima a uma área habitada de uma indústria química que emprega substâncias extremamente tóxicas. $O$ segundo é um evento acidental causado por um descontrole das condiçōes operacionais normais durante o processo de síntese industrial, resultando na emissão dessas substâncias. O terceiro é a natureza apenas parcialmente conhecida dos efeitos previstos, incluindo, além dos efeitos agudos severos, prováveis efeitos crônicos, que se evidenciam até décadas após o acidente ${ }^{10}$. Por exemplo, a dioxina, suspeita de causar câncer em seres humanos, é objeto de dúvidas e controvérsias ate hoje $\mathrm{e}^{4,11,17}$, de modo que a populaçāo atingida ainda é alvo de vigilância epidemiológica e de estudos para melhor identificar os efeitos crônicos. O quarto ingrediente é a demora em se obter informaçōes precisas sobre as substâncias químicas envolvidas, seus efeitos e as medidas de emergência a serem tomadas ${ }^{58}$. 


\section{Agravamento dos Acidentes Químicos Ampliados nos Países de Economia Periférica}

Conforme pode-se observar na Tabelal, até os anos 70 os acidentes químicos ampliados ocorreram predominantemente nos países que ocupavam, ou vinham ocupando, um papel central na economia mundial pós II Guerra Mundial e, assim, concentravam grande parte das industriais, como a Alemanha, a França, a Bélgica, a Inglaterra, os EUA e o Japão. A partir dos anos 70 , com a aceleração do processo de industrialização em outros países que viriam a situar-se na periferia da economia mundial, principalmente na América Latina e Ásia, verifica-se um crescimento e agravamento dos acidentes químicos ampliados.

No ano de 1984, Vila Soc6 (Brasil) e San Juan de Ixhuatepec (México), na América Latina, e Bophal (Índia), na Ásia, foram cenários dos mais graves acidentes químicos ampliados registrados após a II Guerra Mundial em termos de óbitos imediatos. Na noite de 24 de fevereiro ocorreu uma explosão em um oleoduto da Petrobrás, localizado em Vila Socó. Seguiu-se, então, um incêndio de 700 mil litros de gasolina, resultando no registro de 508 6bitos $^{29.6077}$. Em San Juan de Ixhuatepec, na madrugada de 19 de novembro, um vazamento de Gás Liquefeito de Petróleo (GLP), em um dos tanques de estocagem da Petróleos Mexicanos (Pemex), ocasionou uma explosão, seguida de uma série de incêndios e exploşőes subseqüentes, resultando no registro de 550 óbitos ${ }^{6.74}$

Desses acidentes, o de Bophal foi o mais grave já registrado, e tem se constitúfdo no protótipo do acidente químico ampliado nos países de economia periférica ${ }^{13,13,16,69}$. Em Bophal, no fim da noite de 2 dezembro de 1984, iniciou-se um vazamento em um tanque de armazenamento da indústria americana Union Carbide, contendo cerca de 41 toneladas de metil-isocianato. As conseqüências desse acidente sobre a população vizinha a aquela indústria ainda são objeto de dúvidas e controvêrsias. Embora o número oficial de óbitos imediatos registrados nesse acidente tenha sido de 2.500 , as estimativas extra-oficiais variam entre $1.800 \mathrm{e}$ 20.000. O número total de expostos e afetados pela nuvem varia entre 100.000 e 200.000 , e o número de lesionados com permanentes disfunçōes pulmonares é estimado em torno de $20.000^{13.15 .1630 .67 .}$ Em número nāo determinado foram identificados também efeitos oftalmológi$\cos ^{50.67}$, além da suspeita de outros.

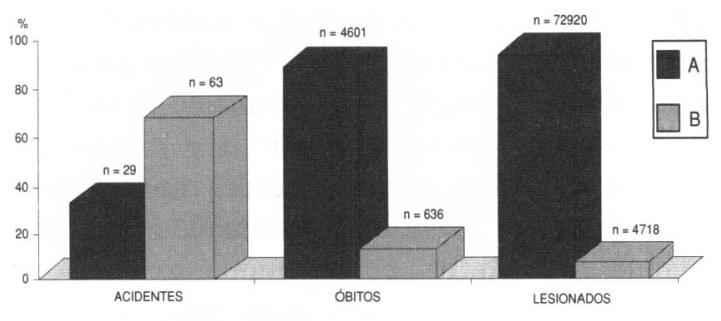

A: Países de economias periféricas

B: Países de economias centrais

*Fonte: $\mathrm{WHO}^{73}$

Figura - Total de acidentes químicos ampliados registrados no mundo entre 1974 - $1987 \mathrm{com}$ mais de 50 óbitos, ou mais de 100 lesionados, ou mais de $50 \mathrm{mi}-$ Indes de dólares em prejuízos (excluindo os prejuízos internos às indústrias).

Os acidentes de Bophal, San Juan de Ixhuatepec e Vila Socó acrescentam novos componentes ao acidente de Seveso, sendo próprios dos países de economia periférica, com características que agravam os acidentes químicos ampliados nesses países. Este agravamento pode ser constatado na Figura, montada a partir de dados da Organização Mundial de Saúde sobre acidentes quínicos ampliados, considerados catastróficos, ocorridos no mundo. A vulnerabilidade social existente nesses países manifestou-se de maneira mais acentuada na Índia, no Brasil e no México, os quais ocupam os três primeiros lugares em termos de 6 bitos por acidentes químicos ampliados, ocorridos no mundo, entre 1945 e 1991, com 5 ou mais óbitos ${ }^{30}$.

Esses três países tiveram seu desenvolvimento entre os anos 60 e 80 caracterizado pelo endividamento externo, forte intervençāo do Estado e grande exclusão social, sendo estas suas formas de inserção na economia mundial'. Nesse período, houve no Brasil, assim como na Índia e no México, uma rápida e desordenada industrialização e um intenso e incontrolado processo de urbanizaçāo, acompanhado de um grande fluxo migratório do campo e das regióes pobres para os grandes centros urbanos ${ }^{t, 35}$. O modelo econômico adotado por esses países combina concentraçảo de capital, exploração da mão-de-obra e abandono ou ornissão do poder público, permitindo o assentamento dessas populações nas áreas periféricas dos grandes centros urbanos, sem acesso aos bens e serviços básicos de saneamento e saúde, ampliando suas situações de riscos ${ }^{32,39}$.

$O$ acidente de Bophal, assim como os de San Juan de Ixhuatepec e Vila Socó, traduzem a 
divisão intemacional do trabalho e dos riscos, caracterizada por dois processos inter-relacionados. O primeiro é o de exportação dos perigos através de transferência de tecnologias, indústrias, produtos e rejeitos perigosos dos países de economia central para os de economia periférica. $O$ segundo é o duplo padrão, onde indústrias multinacionais adotam padróes inferiores de segurança industrial e proteçāo ao meio ambiente, à saúde dos trabalhadores e às comunidades expostas nos países de economia periférica ${ }^{15.16 .39 .44 .69}$. Estes padrões inferiores de segurança indústrial, proteçāo ao meio ambiente e à saúde sāo também muitas vezes encontrados nas indústrias nacionais em comparação com similares nos países de economia central.

Esses processos, inerentes ao modelo de desenvolvimento econômico vigente, são sustentados pela ausência e fragilidade de restrições legais e controle social sobre os riscos químicos nos países de economia periférica, cuja dinâmica da divisāo do trabalho e dos riscos é, de certo modo, também reproduzida em nível interno desses países ${ }^{63}$. $O$ resultado da inter-relaçāo entre divisāo do trabalho e modelos de desenvolvimento nacionais e internacionais implicou a transferência de riscos químicos para as áreas mais pobres e periféricas aos grandes centros urbanos, definindo assim as áreas salubres e seguras das áreas insalubres e inseguras $^{35,35,65}$.

Os acidentes de Bophal, San Juan de Ixhuatepec e Vila Socó ocorreram exatamente nas áreas onde havia a combinação de largo contingente populacional pobre e marginalizado de acesso a bens e serviços, com fontes de riscos de acidentes químicos ampliados, resultando numa grande vulnerabilidade social das mesmas e, conseqüentemente, na morte de centenas ou mesmo milhares de pessoas num único evento. As condições sociais e políticas que contribuíram em 1984 para tomar esses acidentes, os mais graves já registrados nos últimos anos, continuam presentes, cabendo às populaçōes mais pobres dos países de economia periférica arcar com o ônus de suas vidas e saúde para sustentar um modelo econômico iníquo na sua natureza e dinâmica.

\section{Acldentes Químicos Ampllados no Contexto Brasilelro: O Caso do Rio de Janeiro}

O Brasil, em termos de óbitos imediatos, já foi cenário de alguns acidentes quírnicos ampliados, além do de Vila Socó em 1984. No ano de 1983, em Pojuca, na Bahia, o descarrilamento de um comboio ferroviario transportando combustíveis resultou em explosāo e incêndio, provocando o óbito de 43 pessoas, além de grande número de lesionados e desabrigados ${ }^{29,60}$.

O Estado do Rio de Janeiro, o qual já foi cenário de alguns acidentes químicos ampliados com grande número de óbitos imediatos, pode se constituir num exemplo do contexto brasileiro. Em 1951, um acidente com transporte de inflamáveis causou 54 óbitos. Uma explosão, em 1972, na Refinaria Duque de Caxias (Petrobrás), na Baixada Fluminense, resultou no óbito de 38 trabalhadores. No ano de 1984, um incêndio na plataforma de produçāo de petróleo de Enchova (Petrobrás), na Bacia de Campos, teve como consequiência 40 óbitos $^{29,60}$. Nesse mesmo ano, segundo o Sindicato dos Trabalhadores da Indústria Petroquímica do Município de Duque de Caxias, uma explosão na indústria Petroflex resultou em 17 bbitos entre trabalhadores de empreiteiras.

Atualmente, o Estado do Rio de Janeiro possui em seu territorio cerca de $20 \%$ das grandes indústrias químicas em termos de faturamento econômi$\mathrm{co}^{27,48}$. Sua localização geográfica o faz situar entre os pólos industriais químicos de São Paulo, Rio Grande do Sul e Bahia, fazendo com que diariamente haja uma grande circulação de transportes de cargas perigosas em sua rede viária. Estas características, aliadas ao signficativo volume de extração e refino de petróleo, e ao fato de a cidade do Rio de Janeiro possuir um porto de grande porte, contribuem para que haja um grande fluxo de transporte de substâncias químicas no Estado. Além do transporte - principalmente pelas vias rodoviária e marítima e dutos -, há uma considerável produção industrial e armazenamento.

Esses fatores têm contribuído para que venha ocorrendo no Estado número significativo de incidentes/acidentes químicos registrados pelo Serviço de Controle de Poluição Acidental da Fundação Estadual de Engenharia do Meio Ambiente - SCPA-FEEMA - nas atividades de produção, transporte e armazenamento, conforme pode ser verificado na Tabela 2 . Nas atividades de produçāo e transporte, que correspondem a $95 \%$ do total de incidentes/acidentes no período, cerca de $80 \%$ têrn resultado em emissōes diretas ou perda de produtos, tendo alguns envolvido substâncias extremamente perigosas, tais corno cloro, amônia, sulfeto de hidrogênio, chumbo tetraetila e fosgênio. Emissōes acidentais a partir de explosōes e incêndios são também registradas pelo SPCA-FEEMA, situando em torno de $10 \%$ cada um destes tipos de eventos ${ }^{28}$. 
Quanto à distribuição geográfica dos incidentes/acidentes verifica-se na Tabela 2 , que grande parte $(52 \%)$ atingiu principalmente a Regiäo Metropolitana, a de maior densidade demográfica, tendo alguns ocorridos em áreas pobres e de grande contingente populacional. A Regiāo do Médio Paraíba foi a segunda mais atingida (29\%), sendo o rio Paraiba do Sul e seus afluentes, de onde vem a água fornecida para cerca de $80 \%$ da populaçāo do Estado, alvo frequente de emissões acidentais.

A ausência de algumas informaçōes básicas que permitam uma avaliaçāo preliminar dos impactos desses eventos, tais como estimativas de danos ambientais, número de expostos e evacuados, assim como o registro de vítimas, constitui-se num dos limites dos dados do SPCA-FEEMA. levantou 587 eventos com emissões químicas perigosas em três bases de dados dos EUA, em 1986, que resultaram em, no mínimo, 115 óbitos, 2.254 lesionados e 111 evacuações.

Assim, embora os dados do SPCA-FEEMA constituan a principal referência para a investigação sobre acidentes químicos ampliados no Rio de Janeiro, eles se mostram bastante limitados com relaçāo às informaçōes básicas para uma avaliaçāo preliminar dos impactos à saúde que podem estar sendo causados pelos mesmos, tanto para vítimas fatais, como para lesionados $e$ expostos. Considerando que os trabalhadores. ${ }^{43.60}$ e as comunidades ${ }^{4,72}$ dos países de economias periféricas tendem a apresentar uma maior suscetibilidade às emissões de substâncias quî́micas, por conta de fatores tais como má nutrição,

Tabela 2 - Distribuição dos incidentes/acidentes envolvendo substâncias e produtos químicos perigosos no Estado do Rio de Janeiro por regióes de governo $\theta$ as cinco principais atividades económicas, de 1984 a 1993.

\begin{tabular}{|c|c|c|c|c|c|}
\hline $\begin{array}{l}\text { Regiónes de Governo } \\
\text { a Municípios }\end{array}$ & População & $\begin{array}{c}\text { Acidentes } \\
\text { em } \\
\text { Indústrias }\end{array}$ & $\begin{array}{c}\text { Acidentes } \\
\text { de } \\
\text { Transportes }\end{array}$ & $\begin{array}{l}\text { Acidentes } \\
\text { em } \\
\text { Armaz. }\end{array}$ & Total \\
\hline $\begin{array}{l}\text { Regiăo Metropolitana } \\
\text { Regiāo Noroeste Fluminense } \\
\text { Regiåo Norte Fluminense } \\
\text { Regiăo Serrana } \\
\text { Regiảo das Baixadas Litorâneas } \\
\text { Regiåo do Médio Paraíba } \\
\text { Regiåo Centro-Sul Fluminense } \\
\text { Região da Baía da llha Grande }\end{array}$ & $\begin{array}{r}9.536 .064 \\
39.582 \\
489.286 \\
396.695 \\
268.793 \\
668.796 \\
178.250 \\
109.091\end{array}$ & $\begin{array}{r}74 \\
- \\
- \\
- \\
4 \\
31 \\
2\end{array}$ & $\begin{array}{r}121 \\
1 \\
13 \\
11 \\
8 \\
88 \\
27 \\
10\end{array}$ & $\begin{array}{r}20 \\
- \\
- \\
- \\
. \\
- \\
-\end{array}$ & $\begin{array}{r}215 \\
1 \\
13 \\
11 \\
12 \\
119 \\
29 \\
10\end{array}$ \\
\hline Total & 11.686 .557 & 111 & 279 & 20 & 410 \\
\hline
\end{tabular}

Fonte: FIOCRUZ ${ }^{3}$ e FEEMA ${ }^{25}$

Mesmo eventos com substâncias químicas onde as vítimas imediatas foram evidentes, tais como o incêndio na plataforma de Enchova e a explosão na Petroflex, anteriormente comentados, não foram registrados pelo SPCA-FEEMA, não constando também nas estatísticas mundiais utilizadas para o presente artigo $0^{19.29,41,64.73}$.

A existência de estudos realizados em bases de dados sobre esses tipos de acidentes nos EUA, onde eram registrados expostos e vítimas, mostra ser o não-registro de vítimas nos acidentes ocorridos no Rio de Janeiro uma conseqüência da ausência de uma política, particularmente no campo da saúde pública, para esses tipos de eventos. Num estudo sobre acidentes químicos ampliados nas atividades de transporte, entre janeiro de 1982 e setembro de 1983, na California, EUA, Shaw e $\mathrm{col}^{61}$ encontraram uma média de aproximadamente 3 pessoas por acidente para 62 eventos onde havia informações sobre pessoas expostas. Binder ${ }^{12}$ ausência de saneamento básico e prevalência de doenças infecto-contagiosas, o quadro é bastante preocupante.

Os resultados e limites apresentados sobre os dados do SPCA-FEEMA, no Estado do Rio de Janeiro, revelam duas questōes importantes. A primeira refere-se aos riscos que os trabalhadores envolvidos nas atividades de produçāo, transporte e armazenamento de substâncias químicas, bem como as comunidades expostas a esses tipos de eventos, vem sendo submetidos sem, contudo, haver uma legislação e infra-estrutura específicas nos serviços de saúde e órgãos de meio ambiente para o controle e prevençåo dos mesmos. A segunda refere-se à necessidade da saúde pública atuar em conjunto com os 6́rgãos ambientais na formulaçāo de propostas para que algumas das deficiências, tais como a falta de registros adequados, monitoramento e avaliaçāo das consequiências, que por vezes chegam a acarretar em vítimas 
fatais, seja superada e possibilite a formulaçāo de políticas de controle e prevenção de acidentes químicos ampliados adequadas a nossa realidade.

\section{Consideraçōes Finals}

Os acidentes químicos ampliados indubitavelmente constituem problema relevante para a saúde pública, sendo um desafio ainda maior para países de economia periférica como o Brasil. Campos do conhecimento técnico-científico como a Epidemiologia, a Toxicologia, a Engenharia $e$ as Ciências Sociais, através das áreas de saúde do trabalhador, saúde ambiental, planejamento em saúde, entre outras, podem e devem trabalhar em conjunto para enfrentar a queståo dos acidentes químicos ampliados. Dentre os desafios, pode-se citar a preparaçāo dos serviços de saúde e seus profissionais para esses tipos de emergências $^{18,21.36 .57 .68}$, a avaliação dos efeitos sobre a saúde ${ }^{1.68 .12 .253,38.42} \mathrm{e}$ a formulação de políticas públicas para o controle e prevenção dos acidentes químicos ampliados ${ }^{23,3.4,51}$, incluindo a elaboraçāo de planos de contingência em áreas de risco, especialmente nas densamente povoadas. No Brasil, já existem experiências locais neste sentido, tal como a implantação do Sistema de Prevenção de Ríscos de Acidentes Maiores (SIPRAM), em Cubatão ${ }^{20}$, devendo servir de referência para futuras experiências.

Cada uma das atividades de produção, transporte e armazenamento envolvem estratégias e

\section{Referênclas Bibllográflcas}

1. ACKERMANN-LIEBRICH, U. et al. Epidemiologic analysis of an environmental disaster: the schweizerhalle experience. Environ. Res., 58 ; 1-14, 1992.

2. AIR POLLLTION CONTROI ASSOCIATION (APCA). Avoiding and managing environmental damage from major industrial accidents; executive summary of the international conference. J. Air Pollut. Control Ass., 36:127-38, 1986.

3. AMERICAN PLBLIC HEALTH ASSOCIATION, (APHA). The public health implications of the Bophal disaster. Am, J. Public. Health, 77: 230-6, 1987.

4. AXELSON, O. Seveso: Disentangling the Dioxin Enigma? [Editorial]. Epidemiology, 4: 389-92, 1993.

5. BANDARANAYAKE, D. et al, Health consequences of a chemical fire. Int. J. Environ. Health Res., 3:104-14, 1993 medidas particulares para o controle e prevenção, pois cada uma delas possuem características que impedem generalizaçőes em termos do gerenciamento de riscos. Especificamente para a produçāo e o armazenamento, colocam-se como necessidades urgentes a definição, avaliaçāo de riscos e relicenciamento dos sítios perigosos já existentes; a informação sobre os riscos de acidentes $e$ o planejamento de emergências envolvendo trabalhadores e comunidades locais.

Sem a implantação dessas medidas, principalmente através de uma legislação, tal como as existentes nos países da Europa e EUA, o potencial de grandes tragédias ocasionadas por riscos de acidentes químicos ampliados continuará especialmente elevado no Brasil e demais paŕses de economia periférica. Nesse sentido, importante perspectiva para o País encontra-se na proposta do Convênio da Organização Internacional do Trabalho (OIT) sobre a prevenção de acidentes industriais maiores (número 174) $\mathrm{e}$ as recomendaçōes complementares (número 181), adotadas na Conferência Internacional do Trabalho em $1993^{\text {s6 }}$. No seminário Latino-americano promovido pela OIT em 1994, em São Paulo, a delegação brasileira reiterou a necessidade do País aderir ao convênio e respectivas recomendaçóes.

Os primeiros passos para o avanço no controle e prevenção de acidentes químicos ampliados no país já vem sendo dados. Porén, a trajetória ainda é longa e cheia de desafios onde a saúde pública pode e deve contribuir para enfrentá-los.

6. BAXTER, P.J. Major chemical disasters: britain's health services are poorly prepared. BMJ, 302: 61-2, 1991,

7. BECKER, B.K \& EGLER, C.A.G. Brasil: uma nova potência regional na economia mundo São Paulo, Bertrand do Brasil, 1993.

8. BERTAZZI, P.A. Industrial disasters and epidemiology: a review of recent experiences. Scand. J. Work Environ. Health, 15:85$100,1989$.

9. BERTAZZI, P.A. Long-term effects of chemical disasters: lessons and results from Seveso. Total Environ., 106:5-20, 1991.

10. BERTAZZI, P.A. et al. The seveso accident. In: Elliott, P. et al. Geographical and environmental epidemiology: Methods for small area studies. London, Oxford University Press, 1992. p. 342-58.

11. BERTAZZI, P.A. et al. Cancer incidence in a population accidentally exposed to $2,3,7,8$ Tetrachlorodibenzo-p-dioxin. Epidemiology, 4: 398-406, 1993. 
12. BLNDER, $\$$. Deaths injuries and evacuations from acute hazardous materials releases. Amer. J. Public Health, 79:1042-4. 1989.

13. BOWONDER. B. The Bophal incident: implications for developing countries. Entironmentalis. 5:89-103. 1985

14. CARSON. P.A. \& MLNFORD, Reporting and analysis of industrial incidents: 1981-1986. Industr. Entiron., 11: 23-9, 1988.

15. CASTLEMIAN. B.I. \& PLRKAVASTHA, D. The Bophat disaster as a case study in double standards. In: Ives, J.H. Transnational conporations and entironmental controt issues: the export of bazard. London. Routledge and Kegan Paul. 1985. p. 213-33.

16. CASTLEMAI, B.I. \& NAVARRO, V. International mobility of hazardous products, industrics and wastes. Ann. Ret: Public Health, 6:13-21, 1987 .

17. COLLINS. J.C. et al. The mortality experience of norkers exposed to 2.3 .7 .8 -Tetrachlorodjbenzeno-p-dioxin in a trichlorophenol process accident. Epidemiologl, 4: 7-13. 1993.

18. COOKE. M.W. Arrangements for on scene medical care at major incidents. Br. hed.J., 305: $748,1992$.

19. DAVENPORT, J. A study of vapour cloud incidents in industry: a updat. In: Intemational sy'mposizm on loss preiention and safety' promotion in the process industries. 4th. England. Harrogate. 1993. (The Institution of Chemical Engineers Symposium Series).

20. DEAXE, M. et al. Adverse preganancy outocomes in relation to water contamination. Santa Clara County, California, 1980-1981. Amer. I. Epidemiol, 129:894-904. 1989.

21. DeATIEY, C. Hazardous materials exposure mandates integrated patient care. Occup. Health saf. 60: 40-4. 1991.

22. DROGARIS, G. Major accidents reponting sy'stem: lessons leamed from accidents notified. London. Elsevier. 1993.

23. ECONOMIC ELROPEAN COMMLNITIES (EEC). Council Directite of 24 June 1982 on the Vaior Hazards of Certain Industrial Acitivities - 82:501/E.E.C. (Seveso Directive).

24. ELKINS. C.L. \& MAKRIS, J.L. Emergency planning and community right-to-knor: $j$. Amer. Pollut. Control Ass.. 38:243-7. 1988.

25. FER NíCOLA, N.G.G. Aspecto toxicológico de la contaminación ambiental causada por acidentes. Bol. Of. Sanit. Panam. 95: 352-60. 1983.

26. FIOCRLZ:FFEMA Centro de estudos da saúde do trabalhador e ecologia humana da Escola Vacional de Saúde pública. Incidentes/acidentes entoluendo substâncias e produtos químicos perigosos no Estado do Rio de Janeiro - 1984-1993. Rio de Janeiro. CESTEH FXSP FIOCRLZ - SCPA/FEEMA, 1994.

27. FLNDAÇAO GETÍLIO VARGAS. As 500 maiores empresas do Brasil. Conjintit. Econom. 47(8): 52-182, 1993

28. FLNDAÇÄO ESTADLAL DE ENGENHARIA DO MEIO AMBIEXTE (FEEMA). Controle e pre- rença da polução acidental curso teoncoprático. Rio de Janeiro. 1984.

29. GLICKMAX. T.S. et al. Acts of god and acts of mant: recent trends in natural disasters and major industrial accidents. Washington. Resources for the Future. 1992 (Discussion Paper CRU 92-02).

30. GLICKUAN, T.S. et al. Fatal hazardous materials accidents in industry: domestic and foreign experience from 1945 to 1991.

31. GLIDOTTI. T.L. \& CLOUGH. V.M. Occupational health concerns of firefighting. Ann. Ret: Public Health, 13:151-71. 1992.

32. GLILHERME. M.L. Lrbanizaçào, saúde e meio ambiente: o caso da implantaçio do pólo industrial de Cubatào e os seus efeitos urbanos e regionais nos setores da saúde e poluição ambiental. Espaço e Debates. (22):42-53. 1987.

33. HAGLENALER. L. O complexo quimico brasilein: organização e dinâmica imema. Rio de Janeiro. LFRJ/Instituto de Economia Industrial. 1986.

34. HAINES. J.A. Classification of chemical incidents in a global context. São Paulo, 1994. Apresentado ao Simpósio IPCS sobre o Gerenciamento dos Aspectos Ambientais e de Saúde de acidentes com Substâncias Químicas. Sào Paulo. CETESB. 1994]

35. HOGAN, D.J. Migraça ambiente e saúde nas cidades brasileiras. In: Hogan. D.J. \& Vieira. P.F., orgs. Dilemas socioambientais e deseniolimento sustentálel. Sào Paulo. Editora [XICAMP, 1992, p. 149-70

36. HEXTER, P.R. \& MANNION, P.T. Doctors and control of major releases of chemicals. $\mathrm{Br}$. .hed. J. 304:1116-7, 1992

37. ISHIDA. T. et al. The breakdown of an energency system following a gas explosion in Osaka and the subsequent resolution of problems. J. Emergency' Led, 2:183-9. 1985.

38. JARVIS. S.广. et al. Illness associated with contamination of drinking water supplies with phenol. Br. Ked.J., 290:1800-2, 1985.

39. JEYARATAX, J. The transfer of hazardous industries. J. Soc. Occup. Med, 40:123-8. 1990.

40. JEYARATAN, J. Occupational health issues in developing countries. Entiron. Res., 60: $20^{-}-$ 12. 1993.

41. KLFTZ. T. Ieaming from accidents in industm. London, Butternorth. 1988.

42. KOPLAN, J.P. et al. Public health lessons from the Bophal chemical disaster. $J$. Am. hed. Ass.. 264:2795-6, 1990.

43. KORTE. F. \& COLISTON. F. Some consideration of the impact of energy and chemicals on the environment. Regulat. Toxicol, and Pbarmacol, 19:219-27, 1994.

44 . LADOL. J. The export of environmental responsability, Arch. Entiron. Health, 49:6-8, 1994.

45. LAGADEC. P. La cililization du risque: catastrophes tecbnologiques et responsabilité sociale. Paris: Editions Du Seuil. 1981

46. LITOJITZ. T. et al. Occupational and enrironmental exposures reported to poison centers. Am. I. Public Heatth. 83:739-43, 1993. 
47. MARKOWITZ, J.S. et al. Acute health effects among firefighters exposed to a polyvinyl chloride (PVC) fire. Amer. J. Epidemiol, 129:1023-31, 1989.

48. MELHORES e maiores. Exame (ago) 1993.

49. MERCIER: M. Chemical safery as a major challenge for developing countries: role of the international program on chemical safety. Biom. Entiron. Sct, 3: 211-6. 1990.

50. METHA, P.S. et al. Bophal tragedy's health effects: a revien of methyl isocyanato toxicity. J. Am. Med. Ass.. 264: 2781-7, 1990.

51. MORRIS, S.C. ct al. Chemical emergencies: evaluation of guidelines for risk identification. assessment and management. Entiron. Int., 13:305-10, 1987 .

52. MOSSMAX. D.J. et al. Predicting the effects of a pesticide release to the Rhine River. $J$. Water Pollat. Control, 60:1806-12. 1988.

53. MURTI, C.R.K. Industrialization and emerging environmental health issues: lessons from the Bophal disaster. Toxicol. Industr. Health. 7:153-64. 1991.

54. NOGLEIRA. D.P. O Problema das emergencias causadas por produtos quínicos e a saúde da comunidade, Ret'. Bras. Saüde Ocup.. 51:247. 1985

55. ONG, C.N. et al. Facrors influencing the assessment and control of occupational hazards in developing countries. Entimon. Kes. 60: 11223. 1993.

56. ORGANIZACION INTERNACIONAL DEL TRABAJO. (OIT) Seminâtio regional tripantito sobre accidentes industriales marores. Sào Paulo. 1994.

57. ORGANISATION FOR ECONOMIC CO-OPERATION AND DEVELOP YIEXT (OCDE). Health aspects of chemical accidents: gutidance on chemical accident autareness, preparedness and response for bealth professionals and emergency responders. Paris. OCDE. (Environment Mlonogapli n. 81).

58. OTWAY. H. \& AVENDOLA. A. Major hazard information policy in the european community: implications for risk analysis. Risk Analysis, 9:505-12. 1989.

59. PEARCE, F. After Bhopal, Who remembered ixhuatepec? Ner Scientist. 107: 23-3. 1985

60. SEVÁ FILHO. A.O. Crise ambientat, condiçoes de vida e hulas sociais: dilemas da passagem dos séculos XX-XXI. Campinas. Associação Brasileira de Reforma Agrária 1993. (Cadernos da ABRA. $n^{\circ} 1$, rol. 6 -série debate).

61. SHAW. G.M. et al. Characteristics of hazardous materials spills from reporting systems in
California. Am. J. Public Healtb. 76:540-3. 1986.

62. SIPRAM - Sistema de Prevenção de Riscos de Acidentes Maiores. In: Jornada de Trabalho. 1. Cubatào, 1991. Anais". Sào Paulo. FIESP:CIESP'SESI /OIT'Prefeirura de Cubatão, 1992.

63. TEMPLE, W.A. The ICI Fire. Auckland, New Zeland Sào Paulo, [Apresentado ao Simpósio IPCS sobre o Gerenciamento dos Aspectos ambientais e de Saúde de Acidentes com Substâncias químicas. Sào Paulo, 1994].

64. THEYS. J. La Société vulnérable. In: Fabiani. J-L. \& Theys, I. ed. La société tulnérable: etaluer et mattriser les risques. Paris, Presses de L'École Normale Supérieure. 1987. p. 3-35.

65. TORRES. H. A Emergência das inditstrias "sujas" e intensizas em recuros naturais no cenärio industrial brasileiro. Brasília: Instituto Socjedade. Populaçào e Vatureza. 1993. (Documento de Trabalho).

66. LXITED NATIONS ENIIRONMENT PROGRAMME (LXEP), Chenical pollution: $a$ global ozerifeu: Geneva, 1992

67. VARMA. D.R. \& GLEST. I. The Bophal accident and methyt isocyanate toxicity. J. Toxicol. Enuiron. Health, 40:513-29. 1993.

68. VASCONCELLOS. E.S. O atendimento médico de emergência nos acidentes químicos ampliados. Rio de Janeiro. 1995. [Dissertaçào de Mestrado - Escola Nacional de Saúde Pública da Fundaçào Oswaildo Cruz].

69. W'EISS, B. \& CLARKSON. T.W. Toxic chemical disaster and the implications of Bophal for technology transfer . lilbank Quan, 64: 217. 40. 1986.

70. W'EYYE. G.R.S. Liçòes dos grandes desastres das industrias quimicas de flixborough, Seveso e Bophal. Satide e Trabalbo, 2:3-13, 1988.

71. WORCESTER, Incident revives concern over drinking nater safeguards. Ende Rep. Bull. 232: 3-5.1994.

72 . WORLD BANK. Techniques for assessing industrial bazards: a mamual. Washington. World Bank. 1988 (world Bank Technical Paper Number 55).

73. WORLD HEALTH ORGANIZATION. WHO Conission on Health and Fnvironment. Report of the panel on industry'. Genera, 1992.

7. ZEBALLOS. J.L. Explosion de gas en Guadatajara. Mexico. Organización Panamericana de la Salud Programa de Preparativos para Situaciones de Emergencia y Coordinación dęl Socorro en Casos de Desastres. 1992. 


\begin{abstract}
Chemical accidents involving explosions, large fires and leakages of hazardous substances occuring during transport, storage and industrial production of chemicals constitute a real challeng to health, environmental and industrial safety professionals. The aim of this article is to discuss the main questions that this kind of accident provokes, in terms of public helth, particulany in developing countries such es Brazil. The paper defines and characterises these accidents and the various health risk they involve excluding the leakages of hazardous substances during "normal" production in industry - through the combination of quantitative and qualitative information drawn from the intemational literature on the subject. From some exemples of chemical accidents such as occurred in Bophal (india), Vila Soco (Brazil), Sato Paulo (México) and data of the World Health Organization (WHO), the authors seek to show that these events present a worsening, in terms of immediate deaths and injuries, in developing countries. The statistics of chemical accidents which accurred during the last ten years (1984 to 1993) in the State of Rlo de Janeiro are used taken as a frame reference for the pupose of bringing to light the great number of occurrences made with no registration of besic intormation regarding assessment or surveillance. The complexity of causes and consequences, together with the structural problems of developing countries, present public health professionals and institutions, with some important tasks especially those os health risk assessment and the formulation of strategies to prevent and control future major chemical accidents.
\end{abstract}

Chemical accidents. Accidents, occupational. Worker's health. Environmental health. 